\title{
Predicted and actual indoor environmental quality: Verification of occupants' behaviour models in residential buildings
}

\section{Andersen, Rune Korsholm; Fabi, Valentina; Corgnati, Stefano P.}

\section{Published in:}

Energy and Buildings

Link to article, DOI:

10.1016/j.enbuild.2016.05.074

Publication date:

2016

Document Version

Peer reviewed version

Link back to DTU Orbit

Citation (APA):

Andersen, R. K., Fabi, V., \& Corgnati, S. P. (2016). Predicted and actual indoor environmental quality: Verification of occupants' behaviour models in residential buildings. Energy and Buildings, 127, 105-115. https://doi.org/10.1016/j.enbuild.2016.05.074

\section{General rights}

Copyright and moral rights for the publications made accessible in the public portal are retained by the authors and/or other copyright owners and it is a condition of accessing publications that users recognise and abide by the legal requirements associated with these rights.

- Users may download and print one copy of any publication from the public portal for the purpose of private study or research.

- You may not further distribute the material or use it for any profit-making activity or commercial gain

- You may freely distribute the URL identifying the publication in the public portal 
PREDICTED AND ACTUAL INDOOR ENVIRONMENTAL QUALITY: VERIFICATION OF OCCUPANTS' BEHAVIOUR MODELS IN RESIDENTIAL BUILDINGS

Rune K. Andersen ${ }^{1}$, Valentina Fabi ${ }^{2}$, Stefano P. Corgnati ${ }^{2}$

${ }^{1}$ ICIEE, Department of Civil Engineering, Technical University of Denmark, Nils Koppels Allé Building 402, 2800 Kgs. Lyngby, Denmark.

${ }^{2}$ TEBE Research Group, Department of Energy, Politecnico di Torino, Corso Duca degli Abruzzi 24, 10129 Torino, Italy 


\section{ABSTRACT}

Occupants' interactions with the building envelope and building systems can have a large impact on the indoor environment and energy consumption in a building. As a consequence, any realistic forecast of building performance must include realistic models of the occupants' interactions with the building controls (windows, thermostats, solar shading etc.).

During the last decade, studies about stochastic models of occupants' behaviour in relation to control of the indoor environment have been published. Often the overall aim of these models is to enable more reliable predictions of building performance using building energy performance simulations (BEPS). However, the validity of these models has only been sparsely tested.

In this paper, stochastic models of occupants' behaviour from literature were tested against measurements in five apartments. In a monitoring campaign, measurements of indoor temperature, relative humidity and $\mathrm{CO}_{2}$ concentration was measured in the living room and bedroom at five minute intervals in five apartments with similar layout in a building located in Copenhagen, Denmark. Outdoor temperature, relative humidity, wind speed and solar radiation were obtained from a weather station close by.

The stochastic models of window opening and heating set-point adjustments were implemented in the BEPS tool IDA ICE. Two apartments from the monitoring campaign were simulated using the implemented models and the measured weather data. The results were compared to measurements from the monitoring campaign to get an estimate of the forecast's realism.

The simulations resulted in realistic predictions in a sense that the measured values were within or close to the range of the simulated values. The variation in the simulated and measured variables between apartments and over time was similar. However, comparisons of the average stochastic predictions with the measured temperatures, relative humidity and $\mathrm{CO}_{2}$ concentrations revealed that the models did not predict the actual indoor environmental conditions well.

Keywords: Window opening behaviour, Heating set-point adjustments, Stochastic models, Building energy performance simulation, model, Verification

\section{INTRODUCTION}

People usually spend most of their lifetime indoors and make the indoor environment comfortable by heating, cooling, ventilating and illuminating, using non-renewable resources. Occupants' 
behaviour such as thermostat adjustments and window opening can influence the performance of a building to a very high degree [1]. Simulations of indoor environment and energy consumption are becoming increasingly important in the design phase of buildings and most building simulation programs provide possibilities of controlling the simulated environment by adjusting the building control systems. However, discrepancies between simulated and actual behaviour can lead to very large differences between simulation results and actual energy use. This difference has become known as the "performance gap" [2] and a large part of the gap can be attributed to wrong estimations of U-values and to occupants' behaviour [3-6].

When simulating existing buildings, it is possible to overcome the performance gap by calibration of the BEPS model based on data from the existing building. Several papers of model calibration in BEPS, aimed at minimizing the difference between the measured data and predictions from BEPS are published. Lam et al. [7] proposed a method to calibrate an EnergyPlus whole building energy model. Real data of hourly and monthly power, energy and temperature were used to calibrate the lighting, equipment and HVAC system modelled in the Energy Plus tool. O'Neill and Eisenhower [8] defined a methodology to assess the most important parameters affecting the simulation in order to identify parameter combinations that produce the best fit to measured data. Raftery et al. [9] used a case study with high-level of detail to demonstrate a methodology for calibrating whole building energy models by using measured lighting and plug load data in the simulation at hourly intervals. These papers represent a framework on obtaining more accurate results with BEPS programs, when simulating existing buildings and they do not take stochastic models of occupant behaviour and the simulated indoor environment into account. As such, these methodologies cannot be used when simulating new buildings or in cases, where little is known about the occupants and the conditions in the buildings.

In new buildings, U-values can be estimated with relative high certainty since all construction materials are known. And since the performance gap is a result of wrong estimation of U-values and occupants' behaviour, the major part of the performance gap in new buildings originates in differences in simulated and actual behaviour of the occupants. As such, characterisation of occupants' window opening behaviour and the preferences on thermostat set-point is crucial for reliable prediction of building performance (energy consumption, indoor environmental quality, etc.) by means of simulations. The use of stochastic models for the simulation of occupants' interactions with the built environment has greatly affected the modelling approach in the past years. Many attempts have been made to mitigate the gap by providing models of occupants' interactions with the building envelope and controls [10-15]. The goal of many of the models is to 
realistically mimic the occupants' behaviour patterns in building performance simulation programs in an attempt to realistically model the performance of the building. This raises the question: how accurate are the predictions of occupants' behaviour and how accurate and realistic are the simulation results?

All the models [10-15] are based on measurements in occupied buildings and one could effectively claim that they are realistic in the sense that the patterns captured by the models did take place in real buildings. However capturing real patterns is not the same as being able to predict behaviour realistically. Although all the models are based on measurements in buildings, only few of them have been validated or even tested to explore their capability of producing realistic results.

Most evaluation processes do not go beyond assessing the predictive performance on the very same data set the model was inferred from. However, Steyerberg et al. [16] showed that this process can overestimate the performance the model would achieve on an independent data set, even if the data set originated from the same population. Since the ultimate goal of the models is to make realistic predictions in a building before it is built and when very little information about the occupants is available, the models should work independently of the buildings. In order to evaluate if a model is capable of this, it should be tested on another dataset than the one it was inferred from. Thus, this paper does not aim at calibrating and adjustment of BEPS models to replicate the real indoor environmental conditions, but to test the combined predictive power of behaviour models in a context that is different from the one they were inferred from.

When stochastic models are tested on completely external data, i.e. data from other built environments and other occupants [17], the procedure is commonly called external validation. When a high generality is desired, testing the model on external data is crucial. On that account, transparent research designs and clearly defined statistics are needed to evaluate the predictive performance [18]; as well as standardized validation approaches for different kinds of models. An external validation procedure consists of testing the predictive performance of a model in a dataset related but slightly different from the one used for its development. In general, external validation is a procedure quite simple to implement if appropriate data are available on the test dataset, i.e. all the predictors required by the model and all the output variables with respect to which to compare the result of the model. Since the training dataset is different from the test dataset, the results obtained after the application of an external validation procedure may show differences from those calculated applying an internal validation technique. Basically, an external validation procedure assesses the generalizability or transportability of a model from one population of data to another population. 
Examples for a rigorous validation of stochastic occupant behavioural models are scarce. So far, only few papers about validation of behavioural models have been published, regarding both office buildings and residential buildings [10,17,19,20]. Haldi and Robinson (2009) [10] proposed several criteria for assessing the predictive performance of window opening models and use them for model selection and internal evaluation, based on a survey of 14 offices they compare the entire measured data with data from 20 simulations performed for each office. Haldi et al. (2010) [21] validates the same model externally by calibrating it on data acquired from an office building in Austria and testing it on data from another office in Switzerland, and vice versa. Tuohy et al. (2007) [22] show an application of the Humphreys algorithm [14] for a simple office model and compare the simulated results to the longitudinal survey data the algorithm was derived from. The trend is consistent with the survey data, but only a graphical comparison between simulated and predicted data is given for the proportion of occupied days with windows open on the occupied days. Schweiker et al. [17] assessed various models for actions on windows based on data from Swiss and Japanese dwellings applying each data set as training and validation set once. It was found that when applied to other circumstances, the model is not better than chance. Fabi et al. (2015) [19] validated a window opening model based on data from residential buildings near Copenhagen, 15 for the training set and 10 for the validation set applying discrimination criteria and number of actions as validation criteria. Finally Gunay et al. [23] implemented stochastic models of occupants' use of windows, blinds and lights in the BEPS program EnergyPlus [24] and made comparisons between models. However, no comparisons with measured values were made.

Although these papers represent important milestones on the way of assessing the predictive accuracy of stochastic models of occupants' interactions with the built environment (in particular with windows), a considerable space for further research remains to answer the question on which criteria should be used to choose amongst models to be implemented in a building energy performance simulation tool (BEPS) [19]. What is more, the papers have evaluated one action (window openings, light switching or heating/cooling setpoint adjustments) individually and while the probability of one action may depend on other actions (e.g. the probability of increasing the heating setpoint may be lower if the window has just been opened), these conditional probabilities have not yet been tested. Since the ultimate goal of many of these models is to enable realistic predictions in BEPS tools these conditional probabilities need to be handled as well.

In this paper a new validation procedure "validation by simulation" is proposed. The procedure is used to estimate the combined predictive accuracy of two existing behavioural models of both window opening and thermostat set-point adjustments. The procedure is based on an assumption 
that any differences between measurements and simulation results are due to inadequacies in the models of behaviour and not in the BEPS model itself. A case study, in which the actual indoor environmental variables were monitored, was simulated using the stochastic models. The validation was carried out by comparing the simulated indoor environmental variables with the actual measured values in the apartments.

\section{METHOD}

Measurements were compared with simulation results to verify the models of occupants' behaviour. Measurements of indoor environment were carried out in five apartments with two different layouts. The apartments were simulated in the BEPS program IDA ICE [25] using stochastic models of window opening and heating set-points. The results of the simulations (temperature, $\mathrm{RH}$ and $\mathrm{CO}_{2}$ concentration) were compared to the measured values.

\section{Measurements}

In March and April 2014 measurements were carried out in the living room and in the main bedroom of five apartments in a building located in Copenhagen, Denmark. The building is built in 1906, with a solid brick façade and single pane windows. It is supplied by district heating and heated by waterborne radiators with thermostatic radiator valves (TRV). The building consists of five floors with different types of apartments. Only two of these apartments layout were taken into account for the analysis; one is located in the west part of the building (apartments D), the other in the central part (apartments A) (Figure 1). Each apartment consists of a kitchen, a bathroom, a living room, two bedrooms and a corridor.

The following variables were measured continuously in all five apartments.

\section{Indoor environment factors measured every 5 minutes}

- $\quad$ Dry bulb temperature $\left({ }^{\circ} \mathrm{C}\right)$

- Relative humidity (RH) (\%)

- $\mathrm{CO}_{2}$ concentration (ppm)

Outdoor environment acquired from a meteorological measuring stations in 2 minute intervals

- Air temperature $\left({ }^{\circ} \mathrm{C}\right)$

- $\mathrm{RH}(\%)$

- Wind speed $(\mathrm{m} / \mathrm{s})$

- Global Solar radiation(W/m²) 
- Sunshine hours (hourly values)

Sunshine hours are defined as number of hours with sunshine, i.e. with insolation level higher than $120 \mathrm{~W} / \mathrm{m}^{2}$.

The weather data was acquired from a weather station located at the Technical University of Denmark, $11.2 \mathrm{~km}$ from the building. To get an indication of differences in weather between the building and the weather station, a temperature sensor was placed in a shaded position outside the window of one of the apartments. During the measuring period, the mean difference between the temperatures measured by the weather station and the sensor outside the window was $0.2{ }^{\circ} \mathrm{C}$. The maximum difference was $1.7^{\circ} \mathrm{C}$ and $95 \%$ of the observations were within a $0.5{ }^{\circ} \mathrm{C}$ difference.

Besides the measurements, a short questionnaire was distributed to the residents of the five apartments. In the questionnaire, which was returned by all five apartments, the residents stated how often they adjusted heating set-point on the TRVs and they were asked to estimate percentage of equipment use and occupancy for each hour of a typical day in the period. Finally, the residents were asked to state the number of residents in the apartment. This information was used to create profiles of occupancy and electrical equipment in the models.

\section{The simulated building}

This residential building was simulated as a multi zone model (Figure 2 on the right) in the energy simulation software IDA ICE [25]. The simulated apartments were on the first floor and the measurements took place in apartments on the first, third and fourth floor.

The ceiling and floor of the simulated apartments were adiabatic to emulate apartments with identical indoor environmental condition above and below the simulated apartments. The same was true for interior walls that did not face other zones. The nearby buildings were simulated as shading objects to create the outdoor solar shading condition. The characteristics of the constructions are listed in Table 2 and Table 3. The windows consisted of a single pane in a wooden frame. The linear thermal transmittance was set to $0.2 \mathrm{~W} / \mathrm{K} / \mathrm{m}$ for corners where two outer walls meet and 0.2 $\mathrm{W} / \mathrm{K} / \mathrm{m}$ where an internal wall meets an external wall.

To give a picture of which variables were controlled variables ("calibrated" with measured data or assumed based on questionnaires), and which variables were testing variables, Table 1 lists the sources of the variables and parameters used in the simulated model.

The characteristics of the thermal zones are described in Table 4. The kitchen, corridor and bath room did not have radiators. Characteristics of the radiators in the bed rooms and living rooms were obtained from the company in charge of the heat cost allocation [26]. The supply water temperature was controlled based on the outdoor temperature as depicted in Figure 3. 
The choice of TRV model (Passive, Medium or Active use) was based on answers of the question "I interact with the thermostat during one day (never/sometimes/often)" from the questionnaire survey. The schedule for use of electrical equipment was based on the results of the questionnaire survey. A schedule was constructed (Figure 4 - left) in which the electrical equipment was in use 100\% (5 $\left.\mathrm{W} / \mathrm{m}^{2}\right)$ between 7:00-8:00 and 18:00-22:00. The rest of the time it was set to $50 \%\left(2.5 \mathrm{~W} / \mathrm{m}^{2}\right)$. This schedule was used in all the zones except in the kitchen. In the Kitchen the electrical equipment was set to $100 \mathrm{~W}$ in the period from 7:00-8:00 and from 18:30-22:00. From 17:30 to 18:30, the power was $1000 \mathrm{~W}$ to simulate cooking and the rest of the time it was set to $50 \mathrm{~W}$.

The simulated occupancy profile was based on the questionnaire survey. It was defined as in Figure 4 right. The simulated occupants were distributed evenly over the floor area with 0.05 occupants $/ \mathrm{m}^{2}$ (corresponding to 3.8 and 3.1 occupants in apartment A and D respectively). In unoccupied periods, all the windows were closed and the heating set-points remained unchanged.

The lighting was controlled via a fixed schedule which was based on the questionnaire. The lights were on from 6:00-9:00 and from 15:00 to 23:00.

\section{Models of occupants' behaviour}

IDA ICE was used to simulate the building where the measurements took place. Weather data from the measuring period was used as input in the simulations. The window opening and heating set/point was controlled by stochastic models described in [13] and in [27] respectively.

The simulation was run for 10 times producing 10 simulation results (which were different due to the stochastic nature of the behaviour models) for apartments A and D. These were compared to the five sets of measurements from apartments A and D.

\section{Implementation of window opening model}

Andersen et al. (2013) [13] describes four models of window opening depending on the ventilation type (natural/mechanical) and on the ownership (owner-occupied/rental). The apartments were rented and were not equipped with mechanical ventilation so the authors chose to implement the model from group 3 (rented naturally ventilated buildings). This choice was also based on Fabi et al. [19]who found the model to be amongst the two best performing models in relation to predictions of window state and number of openings.

In this model, the window opening behaviour is influenced only by the $\mathrm{CO}_{2}$ concentration. The window closing probability is influenced by the indoor and outdoor temperature, indoor relative humidity and sunshine hours. In Figure 5, the probability of opening a window is depicted for 
different periods of the day as a function of $\mathrm{CO}_{2}$ concentration with the regression model published in [13] (Group 3). In Figure 6, the probability of closing a window is represented for different periods of the day and fixed parameters as a function of indoor temperature.

The probability of opening/closing the window was calculated within the software with the logistic regression formula which is linked to the different parameters defined for the published "Group 3" according to the type of room taken into account (bedroom or living room). Afterwards the model was implemented following the algorithm shown in Figure 7.

The logistic models were used to calculate the probability of opening and closing windows - If the window was closed, the probability to open it was calculated and the closing probability was calculated if the window was open (step 1). These probabilities were compared to random numbers to translate the stochastic probabilities to deterministic signals (step 2). As the given probability is the probability of doing a certain action in a certain time period (in this case 10 minutes), the comparison was made with a random number that changed every 10 minutes. The action occurred when the calculated probability was higher than the random number (step 3).

\section{Implementation of heating set-point adjustment model}

The implemented model for thermostat adjustments was published in [27] who divided the occupants into three categories based on the number of set-point adjustments and inferred three models of TRV interactions (active, medium and passive). The model of active users was used in one of the simulated apartments (apartment D) and the model of medium users was used in the other (apartment A), according to the real occupants' attitude to interact with the heating system.

The models of interactions with TRVs consists of a set of logistic equations (one for increasing and one for decreasing the set-point temperature) and a linear model of the size of the set-point change. In the model of active users, the variables with most influence on the probability to increase the setpoint are the indoor relative humidity, the time of the day and the outdoor temperature. In Figure 8 the probability increasing the set-point temperature is depicted for different periods of the day and fixed indoor relative humidity as a function of outdoor temperature. The probability of decreasing the heating set-point only depends on solar radiation. In Figure 9, the probability of turning down a thermostat is depicted as a function of solar radiation.

As published in [27], the TRV regulation of medium users is related with outdoor temperature and the wind speed. Figure 10 shows the distribution of the turning up probability as a function of the 
wind speed for different outdoor temperatures. In the model of medium users the probability of decreasing the heating set-point temperature is only related to the time of day.

Similar to the window opening macro, the probability of turning up/down the heating controls and the size of the set-point change was calculated by logistic regression. The algorithm used for the prediction of heating set-point adjustment in IDA ICE is expressed in Figure 11.

The logistic models were used to calculate the probability of turning up/down the set-point (step 1). These probabilities were compared to random numbers to translate the probabilities to deterministic signals (step 2). The action (increasing or decreasing the set-point temperature) occurred if the probability of the action was higher than the random number. Following the logics of the diagram, the size of the set-point change was calculated based on a linear regression model (step 3). If the sign of the set-point change corresponded to the action (a positive sign corresponded to the action of turning up; a negative set-point change corresponded to turning down), the set-point was changed. If the sign of the set-point change contradicted the action, the set-point was not changed (step 4).

\section{Data analysis - validation by simulation}

The validation by simulation was carried out by comparison of the measured variables with the simulated ones in duration diagrams. The simulated values were shown as a range between the minimum and the maximum of the 10 simulations.

In each time step (5 minutes) the average values of the 10 simulations were compared to the measured values. This was done for the aggregated results of all five apartments and for each room and apartment individually. Linear regression was performed using the average values of the 10 simulations as dependent variable and the measured values as independent variable. This resulted in an intercept, coefficient and coefficient of determination for each of the 10 rooms (five apartments and two rooms in each apartment) using equation 1.

$$
y=a \cdot x+b
$$

where:

$\mathrm{y}$ is the average of the 10 simulations' physical variable (temperature, relative humidity or $\mathrm{CO}_{2}$ concentration)

$\mathrm{a}$ is the coefficient

$\mathrm{x}$ is the measured values of the physical variable (temperature, relative humidity or $\mathrm{CO}_{2}$ ) 
$\mathrm{b}$ is the intercept.

\section{RESULTS}

Figure 12 to Figure 14 show comparisons between the simulated results and the measurements. Generally the measured temperatures in the bedroom followed the trend of the simulated ones although none of the apartments had measured temperatures which were $100 \%$ within the simulated ranges in both rooms. The average measured temperature in the bedrooms was $1.1{ }^{\circ} \mathrm{C}$ higher $(21.9$ ${ }^{\circ} \mathrm{C}$ vs. $20.8^{\circ} \mathrm{C}$ ) than the average of the 10 simulations.

The measured temperatures in the living rooms had a larger variation (between apartments) than the simulated ones and were on average $1.0^{\circ} \mathrm{C}$ higher than the predictions $\left(22.2^{\circ} \mathrm{C}\right.$ vs. $\left.21.2{ }^{\circ} \mathrm{C}\right)$.

Although the models predicted a larger daily variation in relative humidity than the measurements, the mean values of the simulated and measured values were similar. The gap between predicted and simulated values was $+2 \%$ in the bedrooms and $+5 \%$ in the living rooms $(\mathrm{RH}$ average values were $43 \%$ vs. $42 \%$ in the bedrooms and $44 \%$ vs. $42 \%$ in the living rooms for measured and predicted values, respectively).

In the bed rooms, the predicted $\mathrm{CO}_{2}$ concentrations were in the same range as the measured values and the mean values were similar (911 ppm vs. 873 ppm, equal to a gap of 4\%). In the living rooms the measured mean $\mathrm{CO}_{2}$ concentration was lower than the simulated values (698 ppm vs. 1028 ppm), and the gap between predicted and real $\mathrm{CO}_{2}$ concentration was $-36 \%$. The measured concentrations had a smaller variation between apartments than the simulated values in the bedrooms and especially in the living rooms.

The coefficient of determination $\left(\mathrm{R}^{2}\right)$ of simulated and measured conditions estimates how well the predictions fit the measurements. To perform this analysis, in each time step, the average values (temperature, relative humidity and $\mathrm{CO}_{2}$ concentration) of the 10 simulations were compared to the measurements (Figure 15). A perfect prediction would result in all simulated values being equal to the measured ones (the red line on the figures with equation $y=x$ ). When data from all apartments was aggregated in one figure, the correlations between the average simulated and measured values were weak. Especially the average simulated relative humidity and $\mathrm{CO}_{2}$ concentrations did not match their measured counterparts.

Table 5 reports the results of linear regressions analysis using the average values of the 10 simulations as dependent variable and the measured values as independent variable. Even though 
the simulated $\mathrm{CO}_{2}$ concentrations were in the same range as the measured ones, the fit between the two was poor in all cases.

\section{DISCUSSION}

The idea of the validation by simulation procedure was to compare measured and simulated indoor environmental variables to estimate how well the implemented behaviour models predict reality. The premise of this idea is that the physical properties and other boundary conditions were modelled in accordance with the real conditions under the measurements. If this premise is not met, it will not be possible to determine if differences between simulations and measurements can be attributed to the deviations between the model and reality or to the implemented behaviour models' inabilities to produce realistic predictions. Since the physical properties, occupancy and internal gains were calibrated based on observations and the questionnaire survey it was assumed that the boundary conditions were calibrated to such a degree that they satisfied the premise and that any differences or similarities between simulations and measurements could be attributed to the behaviour models' abilities to produce realistic predictions.

The measured, indoor temperature, relative humidity and $\mathrm{CO}_{2}$ concentration varied greatly between apartments and over time. As such, in any attempts of modelling adaptive actions a fundamental success criterion should be a reliable prediction of indoor environmental conditions in realistic ranges which may be just as important as modelling the buildings' physical properties correctly. Since all of the simulated ranges overlapped with the measurements (except the temperature in two out of 10 rooms) this success criterion was met by the implemented models.

The second success criterion could be to predict conditions that match reality - that is, to predict the correct conditions at the correct time or weather conditions. In this criterion, a perfect match between the simulated indoor environmental conditions and the measurements at each time step should not be expected. However, high performing models of occupant behaviour should be capable of replicating real conditions. If this is not achieved, most probably, the simulated energy consumption will not be realistic. Replication of real conditions implies that the simulated conditions should fluctuate with outdoor conditions within the same ranges as the measurements. E.g. if the measured indoor temperature fluctuates between a specific range at a certain outdoor temperature, high performing models should be able to replicate fluctuations in the same range. That does not mean that the simulated temperature should match the measured temperature in each time step. But if the simulated fluctuations correspond to the measured ranges and the simulated and 
measured mean values resemble each other, a fitted line would be close to $\mathrm{X}=\mathrm{Y}$, when fitting measures vs. simulated values.

On an overall level, the second criterion was not met by the implemented models since the correlations between the predicted and measured conditions were weak. However, it is encouraging that the simulated and the measured temperatures were correlated with a trend line close to $\mathrm{X}=\mathrm{Y}$ in some of the apartments. This means the models were capable of realistic temperature predictions and were able to capture some of the temperature trends in some apartments.

\section{Modelling approach}

The fact that the implemented models performed poorly in some apartments and moderate in other suggest that using one model of the occupants' behaviour will not provide large enough variation in the simulation results to cover several apartments. This variation may be covered by the use of several behaviour profiles or models (e.g. the 16 models presented in [19]). The results suggest that behaviour profiles should be inferred based on data from single dwellings instead of aggregated data from several dwellings since one profile did not cover the full variation in the measured variables. These models could be developed using mixed effects modelling approaches as suggested by [28], where the dwelling is modelled as a stochastic variable.

\section{Assumptions}

The emission of $\mathrm{CO}_{2}$ and water vapour were defined as fixed schedules based on assumptions of occupancy and the occupants' activities in the apartments. These assumptions had an effect on the relative humidity, the $\mathrm{CO}_{2}$ concentration and on the simulated window opening behaviour. Consequently, the poor correlations of measured and average simulated relative humidity values and $\mathrm{CO}_{2}$ concentrations could be a result of a mismatch between the assumed and real production of $\mathrm{CO}_{2}$ and water vapour. The occupancy and the associated vapour and $\mathrm{CO}_{2}$ production could have been modelled as stochastic processes however to our knowledge stochastic occupancy models based on Danish/Scandinavian dwellings do not exist at the moment.

Paramount importance should be given to the building's characteristics and the outdoor climate. These are factor known to play a major role in determining the indoor thermal conditions, since they affect the indoor environmental quality in at least three ways: 
1. Transmission of the external environment through the building fabric. The indoor air conditioning (heating and cooling) set points set from the building occupants can modify the transmission heat according to the differences with the outdoor temperature.

2. Transmission of solar energy and daylight through open or glazed areas. The direct transmission can be controlled by the use of blinds, curtains or glazing.

3. Infiltration of the outside air through doors and windows cracks and holes. The use of windows control ventilation and air movement and insulation air excluders help in reducing the infiltration.

\section{CONCLUSIONS}

A better description of a building's real functioning is not only a scientific problem addressed to improve the capability of a robust prediction of energy consumption through "direct" or "inverse" prediction methods, but also a need of the market. Models of window opening behaviour and heating set-point adjustments were implemented in a BEPS program enabling stochastic predictions of temperatures, relative humidity and $\mathrm{CO}_{2}$ concentrations. Generally, the measured values were within or close to the range of the simulated values and the variation in the simulated variables between apartments and over time was similar to that of the measurements. However, comparisons of the average stochastic simulation outputs with the measured temperatures, relative humidity and $\mathrm{CO}_{2}$ concentrations revealed that the models did not predict the actual indoor environmental conditions well. While it is encouraging that the predicted and measured values were in the same ranges the models inabilities to generally predict the actual indoor environmental conditions calls for an improvement of the implemented models.

\section{REFERENCES}

[1] R. Andersen, The influence of occupants ' behaviour on energy consumption investigated in 290 identical dwellings and in 35 apartments, in: Heal. Build., Brisbane, 2012.

[2] D. Majcen, L.C.M. Itard, H. Visscher, Theoretical vs. actual energy consumption of labelled dwellings in the Netherlands: Discrepancies and policy implications, Energy Policy. 54 (2013) 125-136. doi:10.1016/j.enpol.2012.11.008.

[3] D. Majcen, L. Itard, H. Visscher, Actual and theoretical gas consumption in Dutch dwellings: What causes the differences?, Energy Policy. 61 (2013) 460-471. 
doi:10.1016/j.enpol.2013.06.018.

[4] D. Majcen, L. Itard, H. Visscher, Statistical model of the heating prediction gap in Dutch dwellings: Relative importance of building, household and behavioural characteristics, Energy Build. 105 (2015) 43-59. doi:10.1016/j.enbuild.2015.07.009.

[5] H. Polinder, M. Schweiker, A. Van Der Aa, K. Schakib-Ekbatan, V. Fabi, R. Andersen, et al., Final Report Annex 53 - Occupant behavior and modeling (Separate Document Volume II), 2013.

[6] Total energy use in buildings Analysis and evaluation methods - Final Report of IEA EBC Annex 53, 2013.

[7] K.P. Lam, J. Zhao, E.B. Ydstie, J. Wirick, M. Qi, J. Park, An Energyplus Whole Building Energy Model Calibration Method for Office Buildings Using Occupant Behavior Data Mining and Emprirical Data, in: ASHRAE/IBPSA-USA Build. Simul. Conf., 2014: pp. 160167.

[8] Z. O'Neill, B. Eisenhower, Leveraging the analysis of parametric uncertainty for building energy model calibration, Build. Simul. 6 (2013) 365-377. doi:10.1007/s12273-013-0125-8.

[9] P. Raftery, M. Keane, A. Costa, Calibrating whole building energy models: Detailed case study using hourly measured data, Energy Build. 43 (2011) 3666-3679. doi:10.1016/j.enbuild.2011.09.039.

[10] F. Haldi, D. Robinson, Interactions with window openings by office occupants, Build. Environ. 44 (2009) 2378-2395. doi:10.1016/j.buildenv.2009.03.025.

[11] M. Schweiker, F. Haldi, M. Shukuya, D. Robinson, Verification of stochastic models of window opening behaviour for residential buildings, J. Build. Perform. Simul. 5 (2012) 5574. doi:10.1080/19401493.2011.567422.

[12] R.V. Andersen, B.W. Olesen, J. Toftum, MODELLING OCCUPANTS ' HEATING SETPOINT PREFFERENCES, in: Build. Simul. 2011, Sydney, 2011.

[13] R. Andersen, V. Fabi, J. Toftum, S.P. Corgnati, B.W. Olesen, Window opening behaviour modelled from measurements in Danish dwellings, Build. Environ. 69 (2013) 101-113. doi:10.1016/j.buildenv.2013.07.005.

[14] H.B. Rijal, P. Tuohy, F. Nicol, M. a. Humphreys, a. Samuel, J. Clarke, Development of an adaptive window-opening algorithm to predict the thermal comfort, energy use and overheating in buildings, J. Build. Perform. Simul. 1 (2008) 17-30. 
doi:10.1080/19401490701868448.

[15] H.B. Rijal, P. Tuohy, M. a. Humphreys, J.F. Nicol, A. Samuel, I.A. Raja, et al., Development of Adaptive Algorithms for the Operation of Windows, Fans, and Doors to Predict Thermal Comfort and Energy Use in Pakistani Buildings, ASHRAE Trans. 114 (2009) 555.

[16] E.W. Steyerberg, S.E. Bleeker, H.A. Moll, D.E. Grobbee, K.G. Moons, Internal and external validation of predictive models: a simulation study of bias and precision in small samples, $\mathrm{J}$. Clin. Epidemiol. 56 (2003) 441-447. doi:10.1016/s0895-4356(03)00047-7.

[17] M. Schweiker, F. Haldi, M. Shukuya, D. Robinson, Verification of stochastic models of window opening behaviour for residential buildings, J. Build. Perform. Simul. (2011) 1-20. doi:10.1080/19401493.2011.567422.

[18] A. Mahdavi, F. Tahmasebi, Predicting people's presence in buildings: An empirically based model performance analysis, Energy Build. $86 \quad$ (2015) 349-355. doi:10.1016/j.enbuild.2014.10.027.

[19] V. Fabi, R.K. Andersen, S. Corgnati, Verification of stochastic behavioural models of occupants' interactions with windows in residential buildings, Build. Environ. 94 (2015) 371-383. doi:10.1016/j.buildenv.2015.08.016.

[20] F. Valentina, R.V. Andersen, S.P. Corgnati, Validation of models of users' window opening behaviour in residential buildings, in: Proc. BS2013 13th Conf. Int. Build. Perform. Simul. Assoc. Chambéry, Fr. August 26-28, 2013.

[21] F. Haldi, D. Robinson, C. Pröglhöf, A. Mahdavi, C.- Lausanne, A partial double blind Evaluation of a comprehensive Window Opening Model, in: Proc. BauSIM 2010 Conf., Vienna, 2010.

[22] P. Tuohy, H.B. Rijal, M. a Humphreys, J.F. Nicol, A. Samuel, J. Clarke, COMFORT DRIVEN ADAPTIVE WINDOW OPENING BEHAVIOR AND THE INFLUENCE OF BUILDING DESIGN Energy Systems Research Unit, University of Strathclyde, Glasgow G1 1XJ , UK Oxford Institute for Sustainable Development, Oxford Brookes University , OX3 0BP , UK, in: Build. Simualtion, 2007: pp. 717-724.

[23] H.B. Gunay, W. illia. O'Brien, I. Beausoleil-Morrison, Implementation and comparison of existing occupant behaviour models in EnergyPlus, J. Build. Perform. Simul. (2015). doi:10.1080/19401493.2015.1102969. 
[24] U.S.D. of E. DOE, T.N.R.E.L. NREL, EnergyPlus TM, (n.d.).

[25] A. EQUA Simulation, IDA ICE version 4.6.2 - IDA Indoor Climate and Energy, (2015).

[26] Brunata A/S, n.d.

[27] V. Fabi, R.V. Andersen, S.P. Corgnati, Influence of occupant 's heating set-point preferences on indoor environmental quality and heating demand in residential buildings, HVAC\&R Res. 19 (2013) 635-645. doi:10.1080/10789669.2013.789372.

[28] F. Haldi, A PROBABILISTIC MODEL TO PREDICT BUILDIN G OCCUPANTS , DIVERSITY TOWARDS THEIR INTERACTIONS WITH THE BUILDING ENVELOPE, in: Proc. BS2013 13th Conf. Int. Build. Perform. Simul. Assoc. Chambéry, Fr. August 26-28, 2012: pp. 1475-1482. 

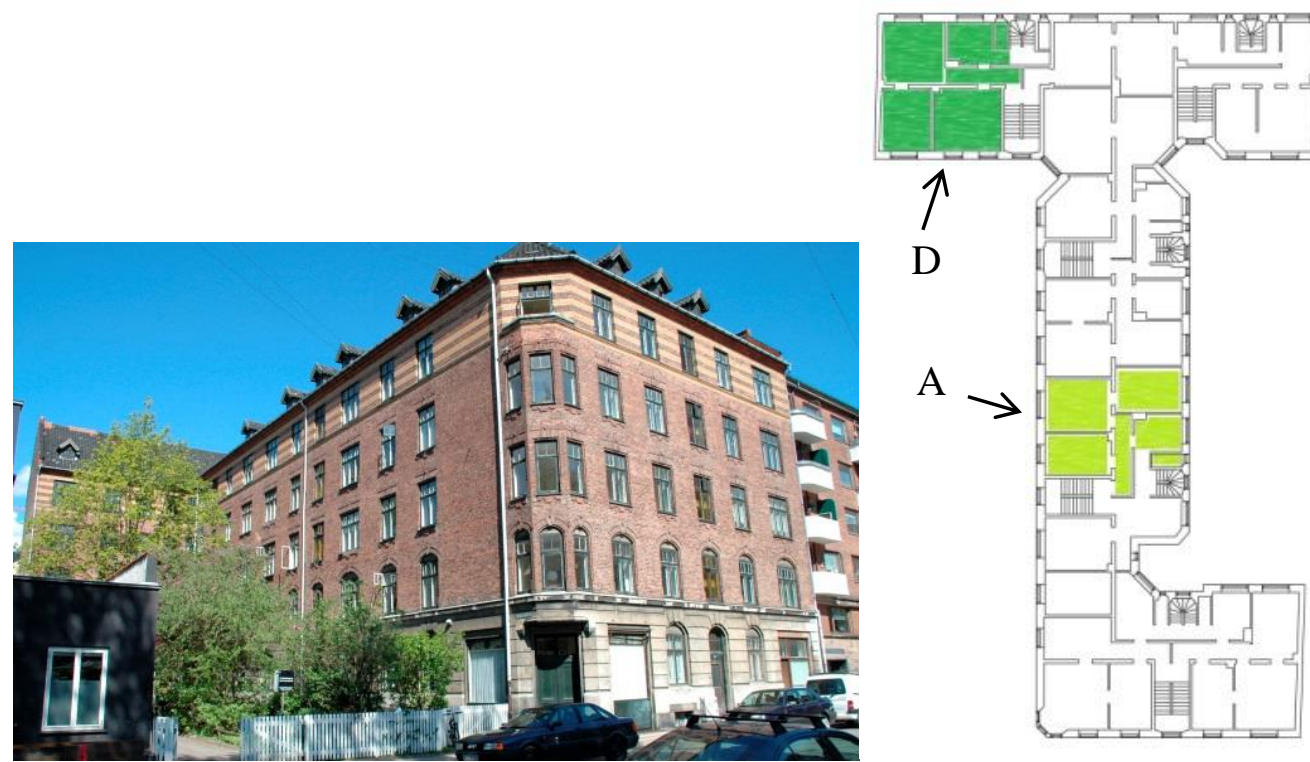

Figure 1: The building where the measurements took place.
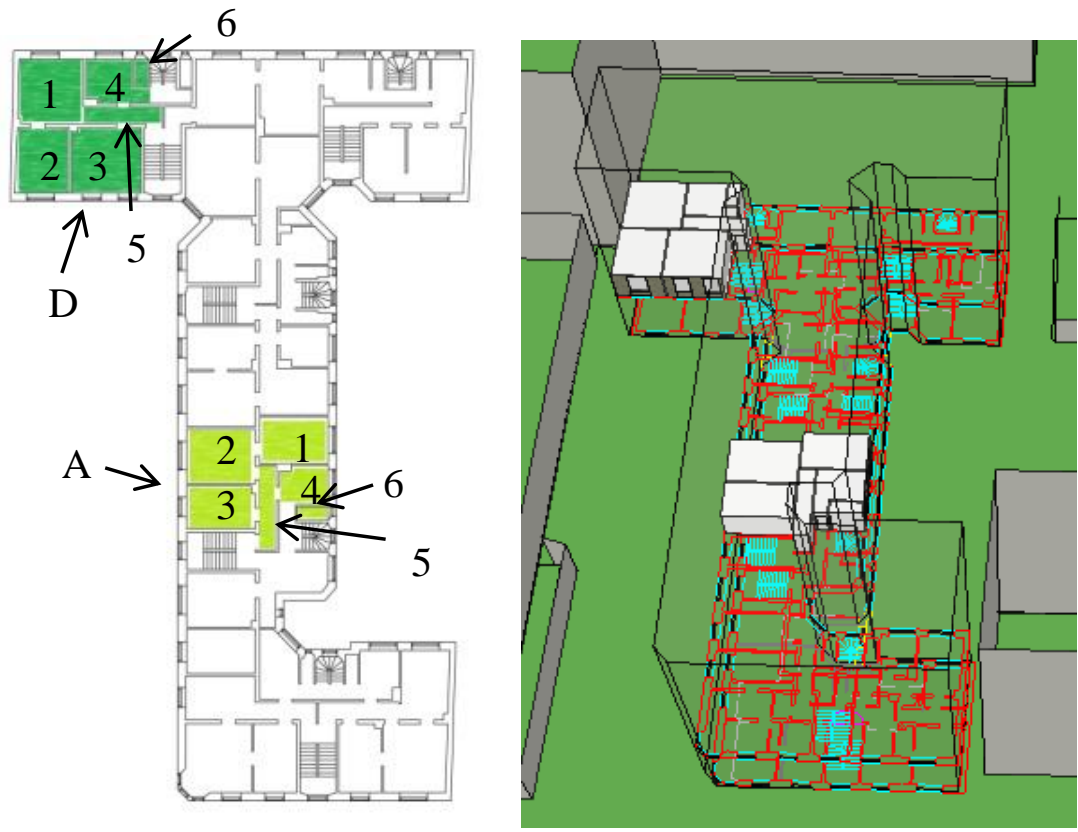

Figure 2 - CAD and IDA ICE designs building. The letters " $A$ " and " $D$ " refer to the apartments and the numbers 1-6 refer to the thermal zones. 


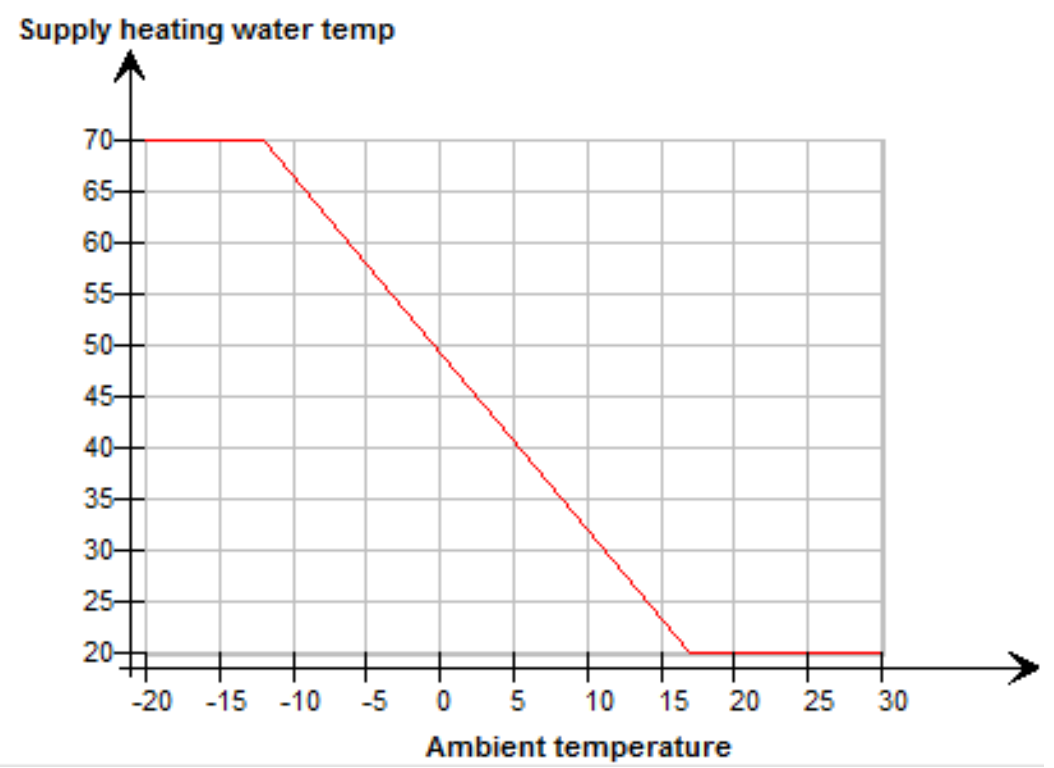

Figure 3 -control of the supply water temperature for the radiators as a function of the outdoor ambient temperature.

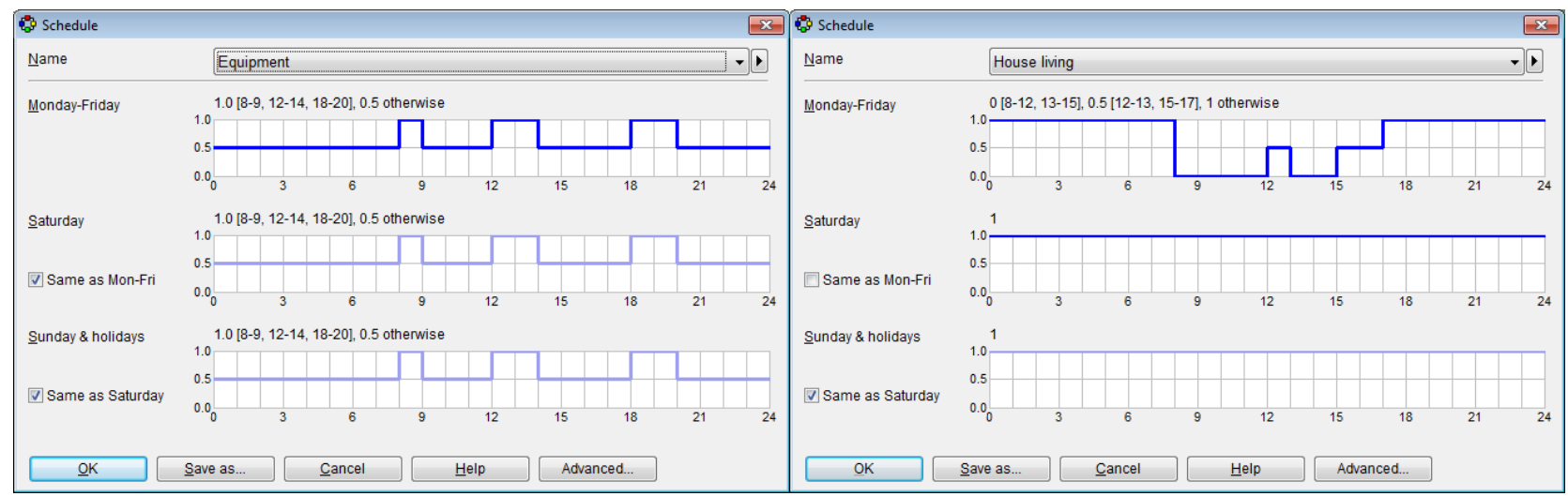

Figure 4 - Schedules for electric equipment (left) and occupancy (right) 


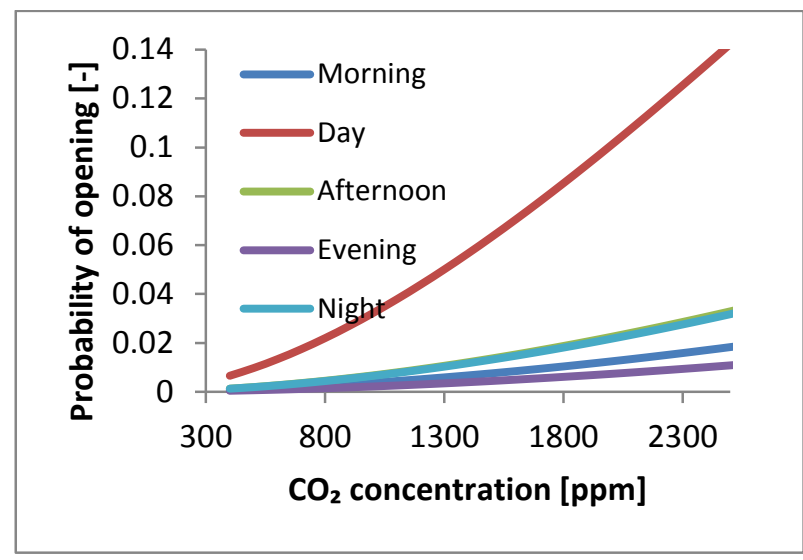

Figure 5 - Graphical representation of the window opening model for bedroom and living room of Group 3 (regression coefficient from [13]).
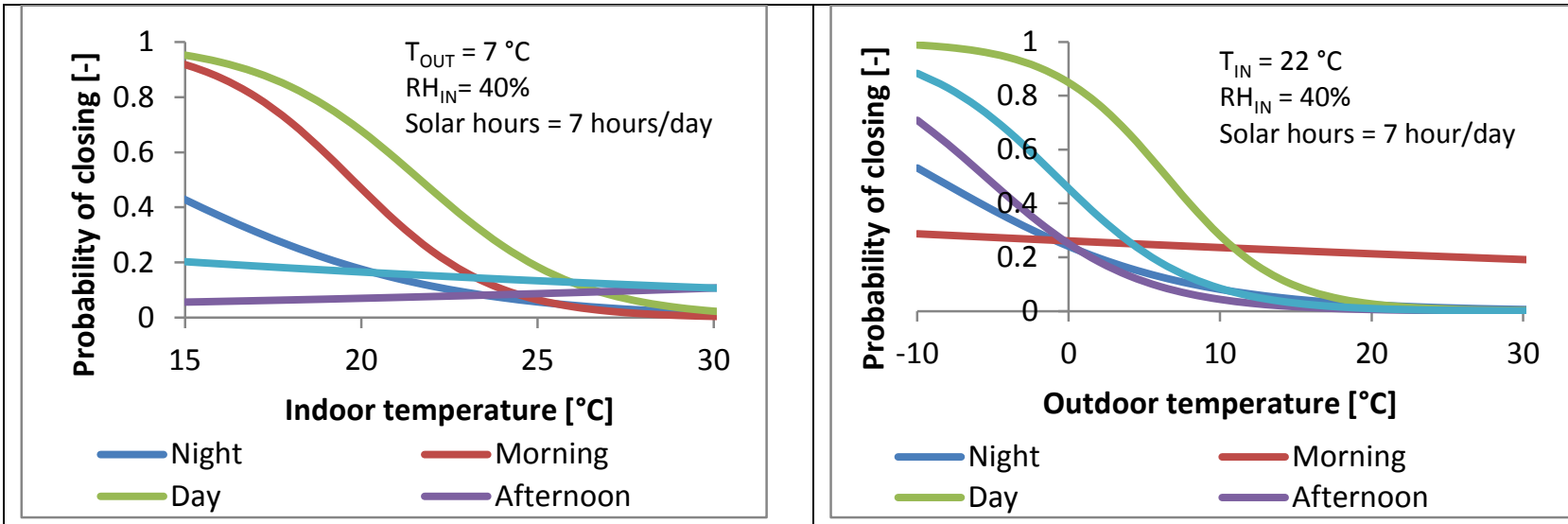

Figure 6 - Graphical representation of the window closing model for bedroom from Group 3. The probability of closing a window is depicted for different periods of the day and fixed parameters as a function of indoor (left) and outdoor (right) temperature. 


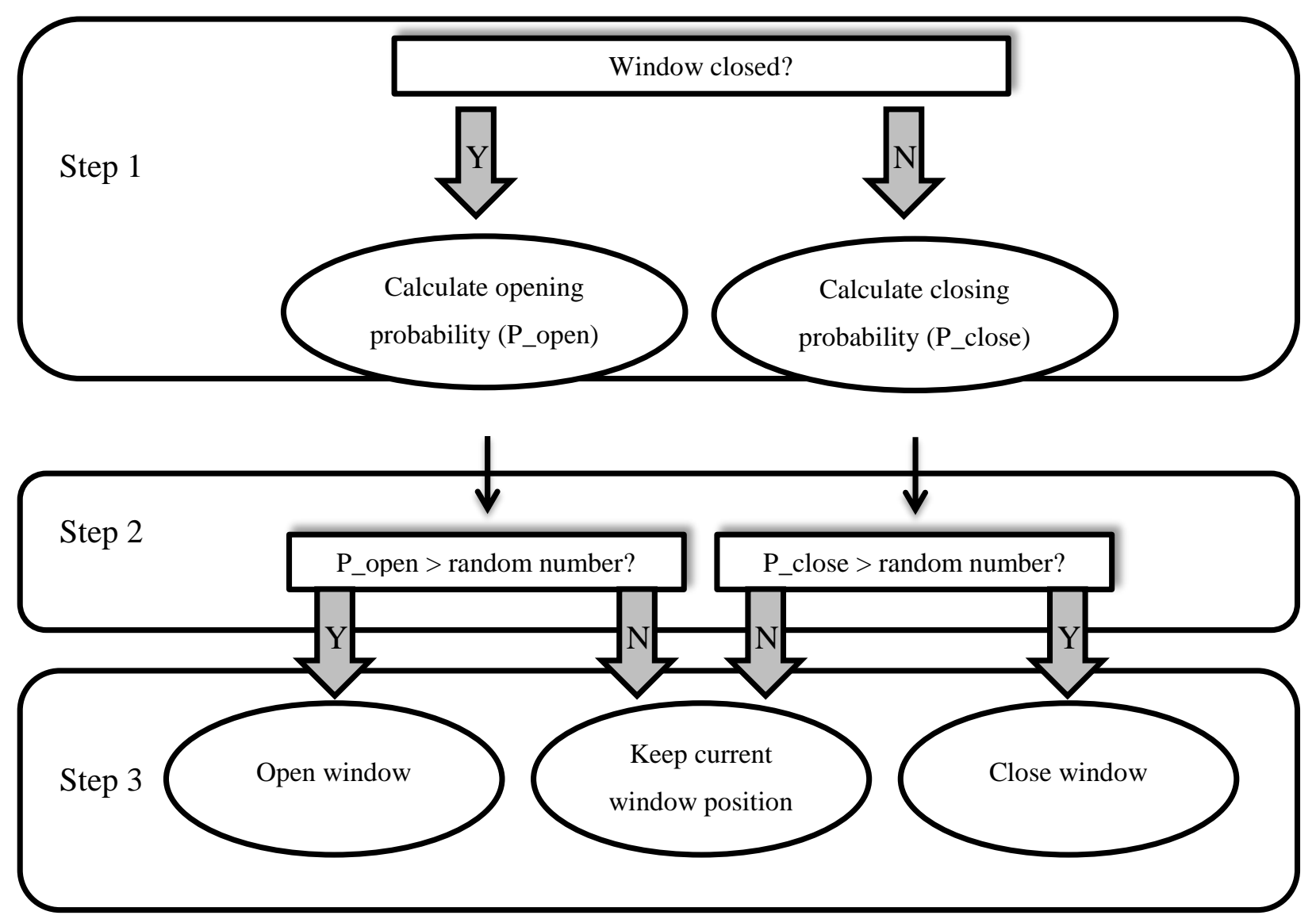

Figure 7 - Algorithm for window opening and closing model 


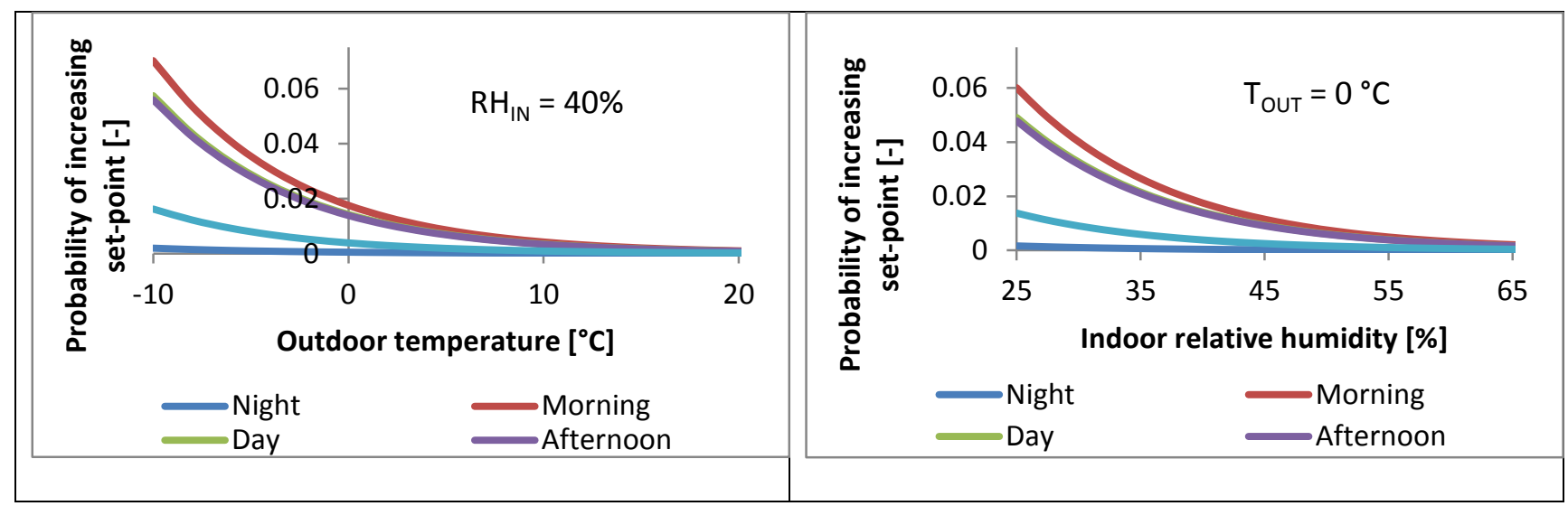

Figure 8 - Graphical representation of the thermostat turning up model for active users.

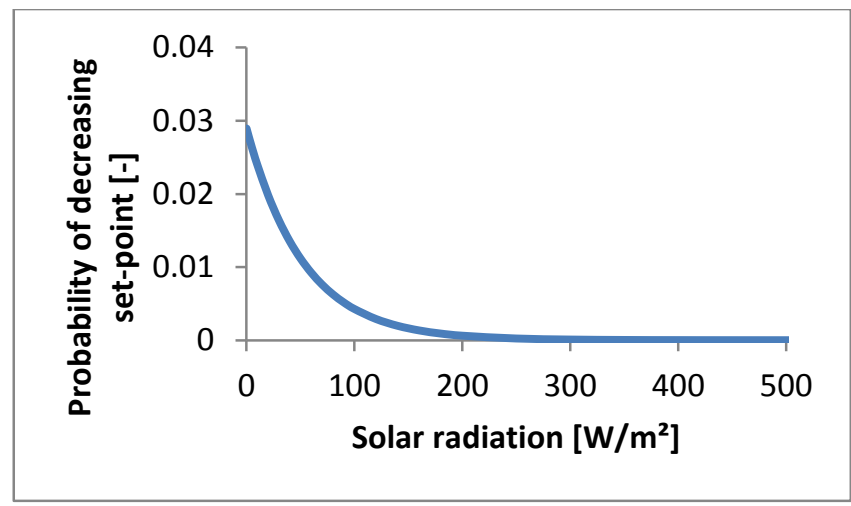

Figure 9 - Graphical representation of the thermostat turning down model for active users. 


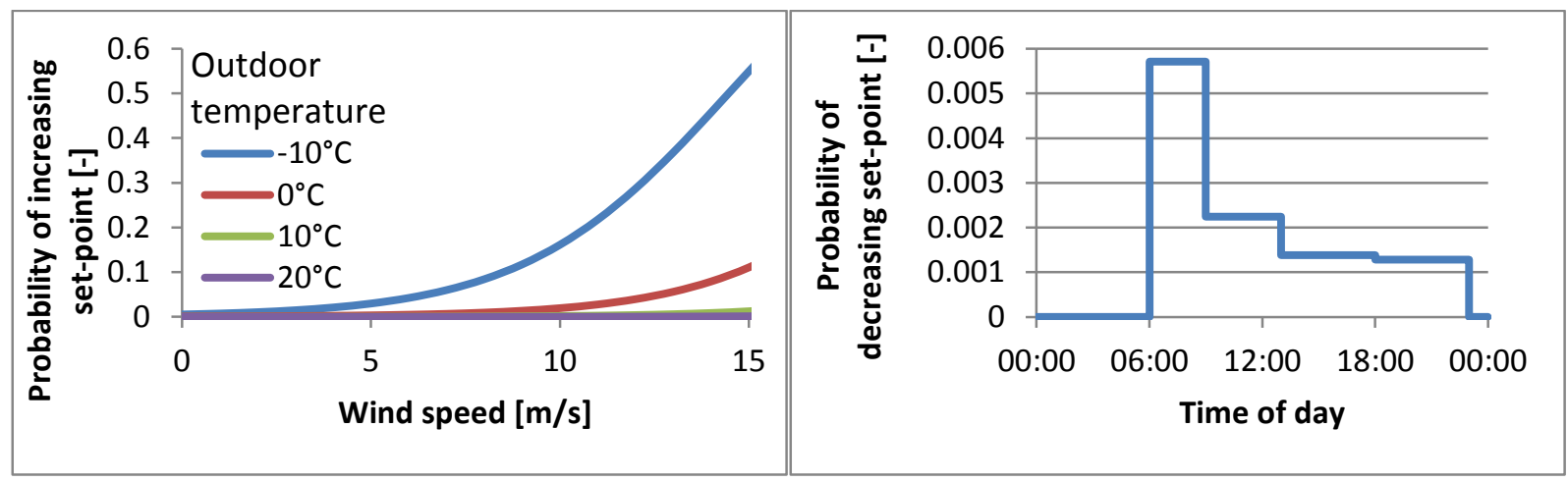

Figure 10 - Graphical representation of the thermostat turning up (left) and down (right) model for medium users. 


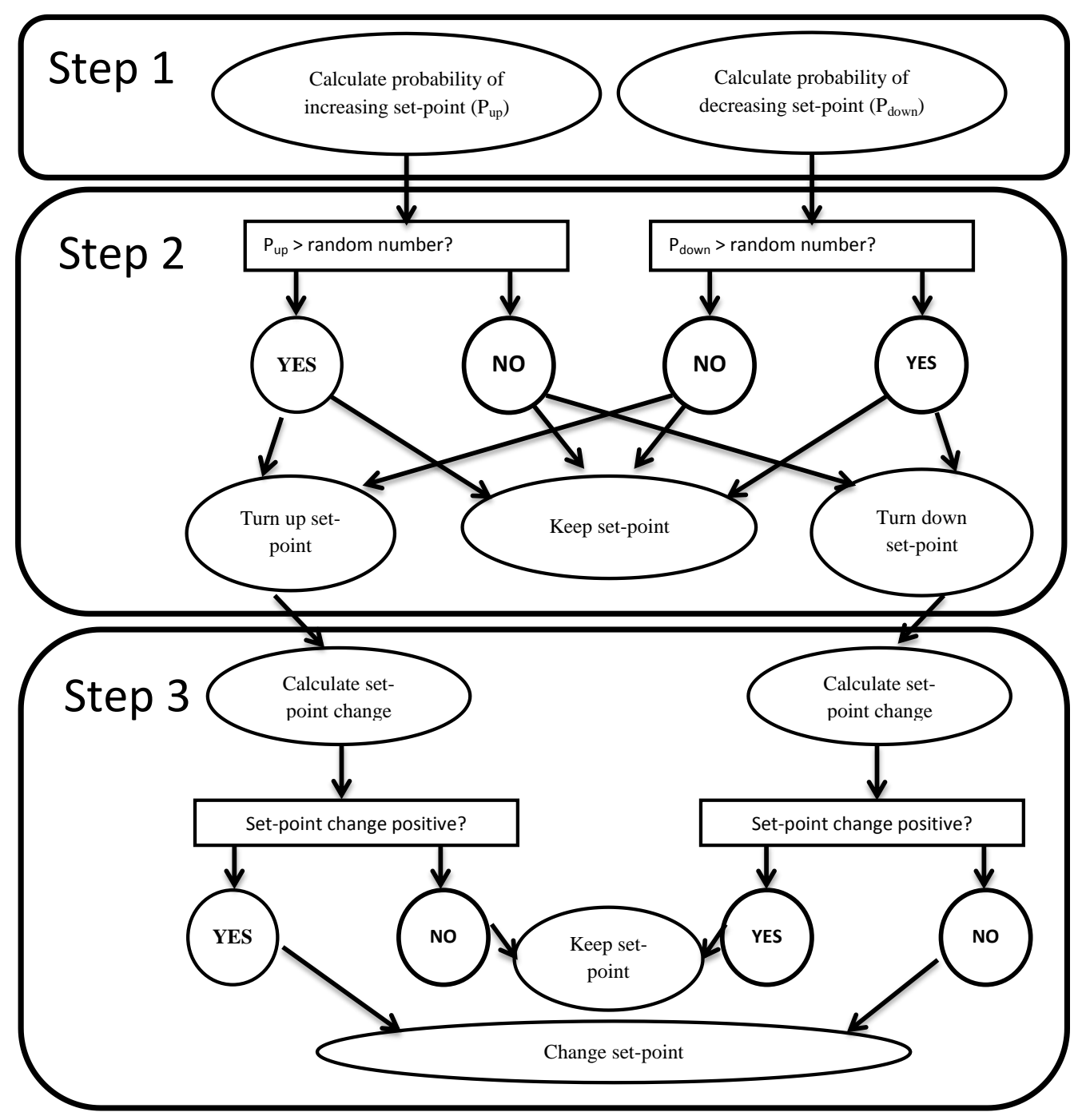

Figure 11 - Algorithm for heating set-point model. Figure adapted from [27] 

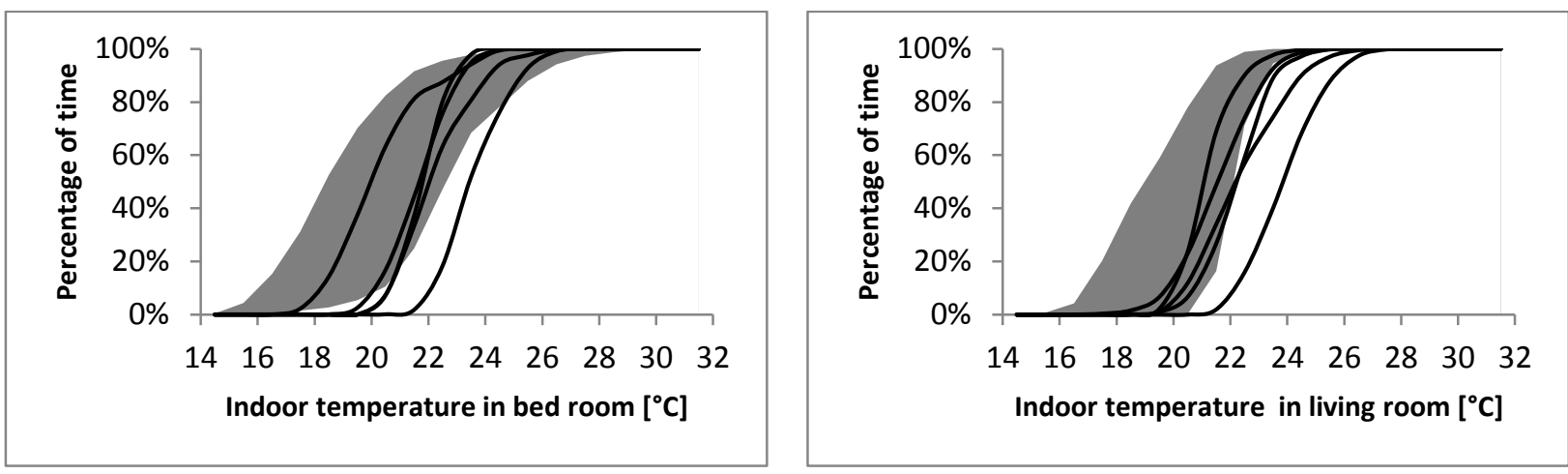

Figure 12 -Duration diagrams of indoor temperatures in the bed rooms (left) and in the living rooms (right). The figures show the percentage of time (March and April 2014) with temperatures lower than values on the $x$-axis. The grey area shows the range of the simulated values from the 10 simulations and the black curves show the measured values in the five apartments.
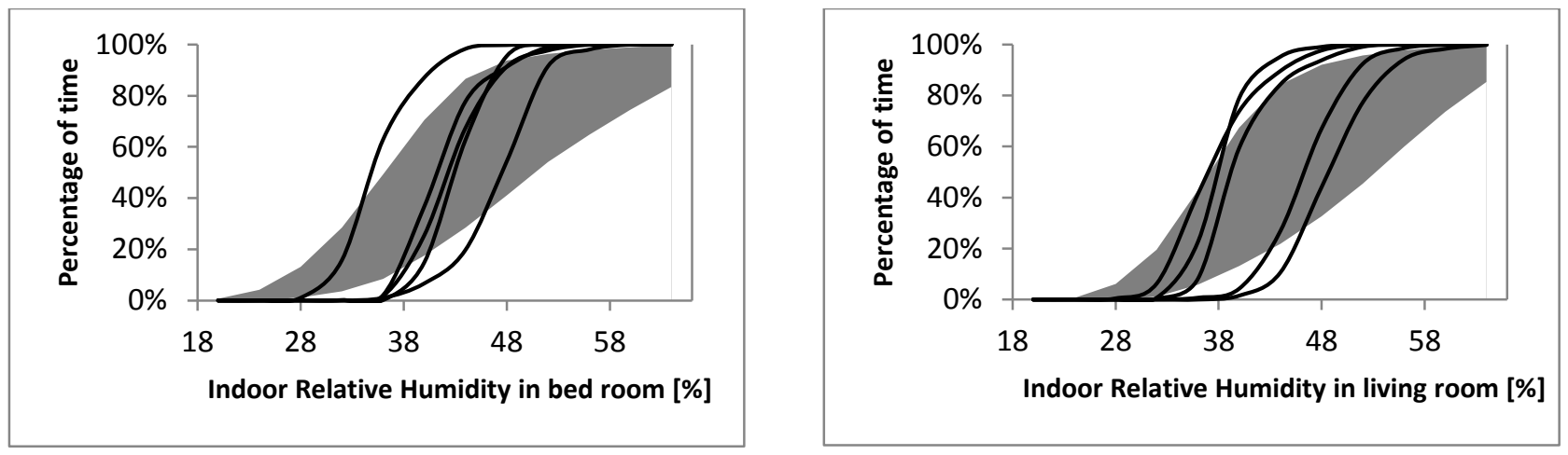

Figure 13 - Duration diagrams of relative humidity in the bed rooms (left) and in the living rooms (right). The figures show the percentage of time (March and April 2014) with relative humidity lower than the values on the $x$-axis. The grey area shows the range of the simulated values from the 10 simulations and the black curves show the measured values in the five apartments. 

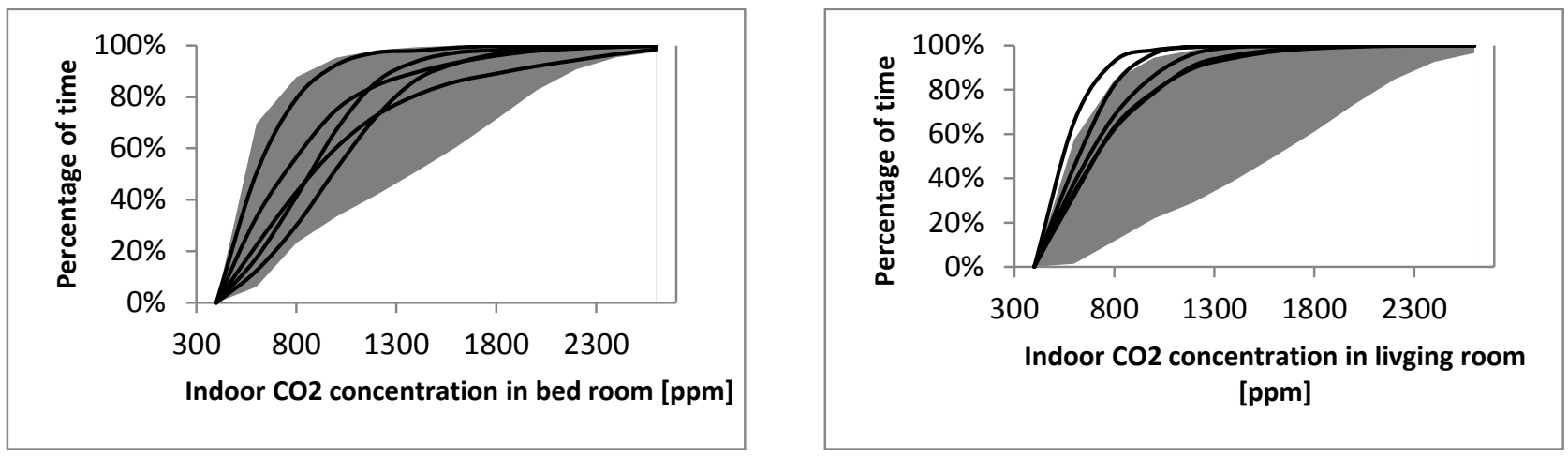

Figure 14 - Duration diagrams of $\mathrm{CO}_{2}$ concentration in the bed rooms (left) and in the living rooms (right). The figures show the percentage of time (March and April 2014) with $\mathrm{CO}_{2}$ concentrations lower than the values on the x-axis. The grey area shows the range of the simulated values from the 10 simulations and the black curves show the measured values in the five apartments.
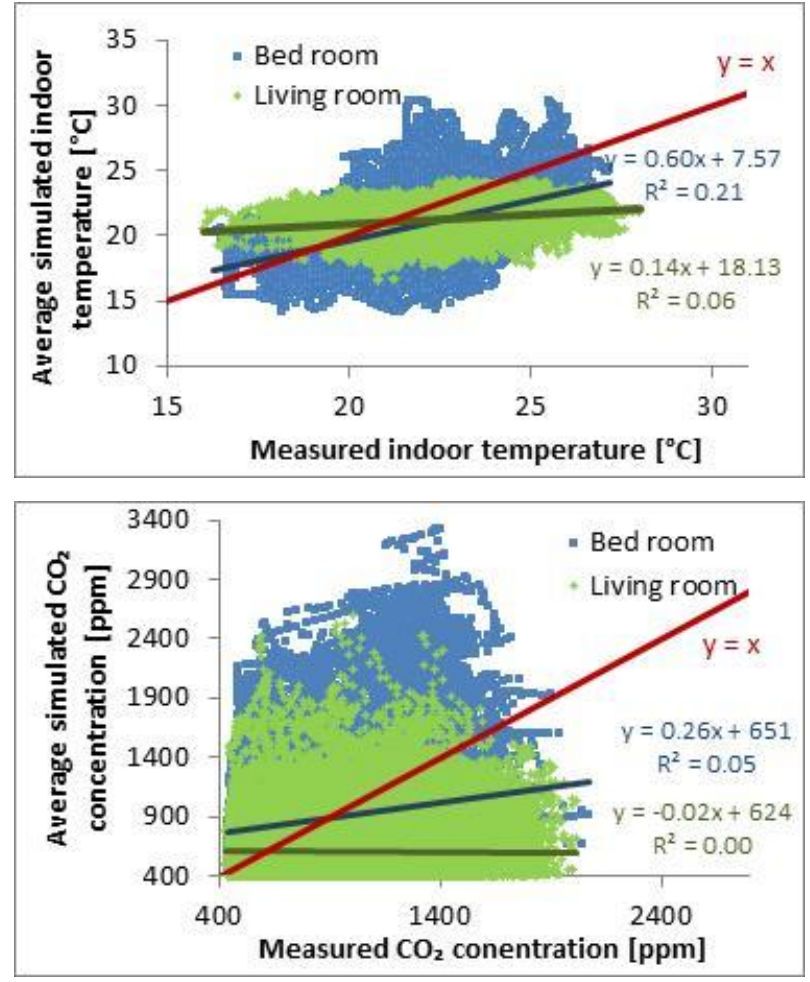


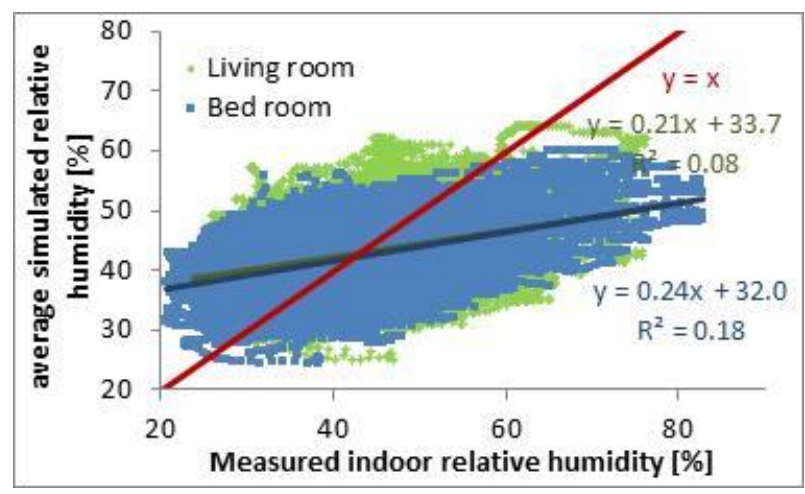

Figure 15 - Comparison of measured and simulated temperatures (top), Relative humidity (middle) and $\mathrm{CO}_{2}$ concentration (bottom). The figure is based on averages of the 10 simulations compared to the measurements in all five apartments. The lines represent linear fits of all measurements in the bed room (blue) and in the living room (green). A perfect prediction would result in the red line $Y=X$. 
Table 1 - List of variables and parameters in the IDA ICE model of the building

\begin{tabular}{|l|l|}
\hline $\begin{array}{l}\text { Variable and parameter in } \\
\text { the BEPS model }\end{array}$ & source \\
\hline $\begin{array}{l}\text { Thermal properties of } \\
\text { envelope }\end{array}$ & $\begin{array}{l}\text { Observations and assumptions based on typical construction } \\
\text { methods in the early 20th century - see Table 2 to 4 }\end{array}$ \\
\hline Weather data & Measured 11.2 km from the building \\
\hline Use of electric equipment & Assumptions based on questionnaire survey - see Figure 4 \\
\hline Use of electric light & Assumptions based on questionnaire survey \\
\hline Occupancy & Assumptions based on questionnaire survey - see Figure 4 \\
\hline Properties of radiators supply water & Data from heat cost allocation company \\
\hline $\begin{array}{l}\text { Control of } \\
\text { temperature }\end{array}$ & $\begin{array}{l}\text { Assumption based on typical control strategies in Denmark - see } \\
\text { Figure 3 }\end{array}$ \\
\hline Window opening & Testing variable \\
\hline Heating set-point & $\begin{array}{l}\text { Testing variable - choice of model based on questionnaire survey } \\
\text { - see Table 4 }\end{array}$ \\
\hline
\end{tabular}

Table $\mathbf{2}$ - characteristics of the opaque constructions in the building model

\begin{tabular}{|l|l|l|l|}
\hline Opaque elements & Thickness [m] & U-value [W/m² $\mathbf{K}]$ & Description \\
\hline External walls & 0.36 & 1.27 & Brick \\
\hline Internal walls & 0.13 & 2.54 & Brick \\
\hline Internal floors & 0.41 & $0.23^{*}$ & $\begin{array}{l}\text { Wooden flooring, } \\
\text { wooden beams with } \\
\text { clay or silt, wooden } \\
\text { ceiling }\end{array}$ \\
\hline
\end{tabular}

* The floors and ceilings had an adiabatic boundary in the middle of the construction.

Table 3 - Characteristics of the transparent elements (windows) in the building model

\begin{tabular}{|l|l|l|l|l|l|}
\hline $\begin{array}{l}\text { Transparent } \\
\text { elements }\end{array}$ & $\begin{array}{l}\text { g-value } \\
\text { (Solar heat } \\
\text { gain } \\
\text { coefficient) } \\
{[-]}\end{array}$ & $\begin{array}{l}\text { T-value (Solar } \\
\text { transmittance) } \\
{[-]}\end{array}$ & $\begin{array}{l}\text { Visible } \\
\text { transmittance } \\
{[-]}\end{array}$ & $\begin{array}{l}\text { U-value } \\
{\left[\mathbf{W} / \mathbf{m}^{2} \mathbf{K}\right]}\end{array}$ & $\begin{array}{l}\text { linear thermal } \\
\text { transmittance } \\
\text { along window } \\
\text { perimeter } \\
{[\mathbf{W} / \mathbf{K} / \mathbf{m}]}\end{array}$ \\
\hline $\begin{array}{l}\text { Single pane } \\
\text { window }\end{array}$ & 0.85 & 0.83 & 0.9 & 5.8 & 0.06 \\
\hline
\end{tabular}


Table 4 - Characteristics of the zones in the building model

\begin{tabular}{|c|c|c|c|c|c|c|c|c|c|c|c|c|}
\hline Zone & $\mathrm{A} 1$ & $\mathrm{~A} 2$ & A3 & A4 & A5 & A6 & D1 & D2 & D3 & D4 & D5 & D6 \\
\hline $\begin{array}{l}\text { Descrip } \\
\text { tion }\end{array}$ & $\begin{array}{l}\text { Bed } \\
\text { room }\end{array}$ & $\begin{array}{l}\text { Bed } \\
\text { room }\end{array}$ & $\begin{array}{l}\text { Livin } \\
\mathrm{g} \\
\text { room }\end{array}$ & $\begin{array}{l}\text { Kitch } \\
\text { en }\end{array}$ & $\begin{array}{l}\text { corri } \\
\text { dor }\end{array}$ & $\begin{array}{l}\text { bathro } \\
\text { om }\end{array}$ & $\begin{array}{l}\text { Livi } \\
\text { ng } \\
\text { roo } \\
\text { m }\end{array}$ & $\begin{array}{l}\text { Bed } \\
\text { roo } \\
m\end{array}$ & $\begin{array}{l}\text { Bed } \\
\text { roo } \\
m\end{array}$ & $\begin{array}{l}\text { Kitch } \\
\text { en }\end{array}$ & $\begin{array}{l}\text { Corri } \\
\text { dor }\end{array}$ & $\begin{array}{l}\text { Bat } \\
h \\
\text { roo } \\
\mathrm{m}\end{array}$ \\
\hline $\begin{array}{l}\text { Floor } \\
\text { area } \\
{\left[\mathrm{m}^{2}\right]} \\
\end{array}$ & 13.9 & 17.5 & 13.7 & 9.5 & 6.0 & 2.1 & 20.8 & 16.9 & 20.3 & 10.9 & 5.8 & 2.1 \\
\hline $\begin{array}{l}\text { Windo } \\
\text { W area } \\
{\left[\mathrm{m}^{2}\right]}\end{array}$ & 2.7 & 2.7 & 2.2 & 2.7 & 0 & 0.7 & 2.7 & 2.7 & 2.7 & 4.4 & 0 & 0.7 \\
\hline $\begin{array}{l}\text { Max } \\
\text { heating } \\
\text { power } \\
{[\mathrm{W}]}\end{array}$ & 700 & 550 & 1800 & 0 & 0 & 0 & $\begin{array}{l}150 \\
0\end{array}$ & 700 & $\begin{array}{l}200 \\
0\end{array}$ & 0 & 0 & 0 \\
\hline $\begin{array}{l}\text { Windo } \\
\mathrm{w} \\
\text { opening } \\
\text { area } \\
{\left[\mathrm{m}^{2}\right]}\end{array}$ & 0.27 & 0.27 & 0.22 & 0.27 & - & 0.07 & 0.27 & - & 0.27 & 0.44 & - & $\begin{array}{l}0.0 \\
7\end{array}$ \\
\hline $\begin{array}{l}\text { TRV } \\
\text { model }\end{array}$ & $\begin{array}{l}\text { Medi } \\
\text { um }\end{array}$ & $\begin{array}{l}\text { Medi } \\
\text { um }\end{array}$ & $\begin{array}{l}\text { Medi } \\
\text { um }\end{array}$ & - & - & - & $\begin{array}{l}\text { Acti } \\
\text { ve }\end{array}$ & $\begin{array}{l}\text { Acti } \\
\text { ve }\end{array}$ & $\begin{array}{l}\text { Acti } \\
\text { ve }\end{array}$ & - & - & - \\
\hline
\end{tabular}

* at design conditions: air temperature of $20^{\circ} \mathrm{C}$, supply temperature of $55^{\circ} \mathrm{C}$ and return temperature of $45^{\circ} \mathrm{C}$. 
Table 5: coefficients of determination, intercepts and coefficients of linear fit between average of the 10 simulations and the measurements in each apartment. A perfect fit would have the following characteristics: intercept $=0$, Coefficient $=1$ and $R^{2}=1$.

\begin{tabular}{|c|c|c|c|c|c|c|c|c|c|c|}
\hline \multirow[b]{2}{*}{$\begin{array}{l}\text { Roo } \\
\text { m }\end{array}$} & \multirow[b]{2}{*}{$\begin{array}{l}\text { Apar } \\
\text { tmen } \\
t\end{array}$} & \multicolumn{3}{|c|}{ Temperature } & \multicolumn{3}{|c|}{ Relative humidity } & \multicolumn{3}{|c|}{$\mathrm{CO}_{2}$ concentration } \\
\hline & & $\begin{array}{l}\text { interce } \\
\text { pt }\end{array}$ & $\begin{array}{l}\text { coefficie } \\
\text { nt }\end{array}$ & $\mathrm{R}^{2}$ & $\begin{array}{l}\text { interc } \\
\text { ept }\end{array}$ & $\begin{array}{l}\text { coeffic } \\
\text { ient }\end{array}$ & $\mathrm{R}^{2}$ & $\begin{array}{l}\text { interc } \\
\text { ept }\end{array}$ & $\begin{array}{l}\text { coeffic } \\
\text { ient }\end{array}$ & $\mathrm{R}^{2}$ \\
\hline \multirow{5}{*}{$\begin{array}{l}\text { bed } \\
\text { roo } \\
\text { m }\end{array}$} & A1 & 0.74 & 0.97 & 0.11 & 2.95 & 0.91 & 0.10 & & & \\
\hline & A3 & -1.78 & 1.00 & 0.26 & 7.65 & 0.94 & 0.17 & 797.5 & 0.17 & 0.01 \\
\hline & D1 & 15.30 & 0.21 & 0.02 & -6.93 & 1.25 & 0.26 & 540 & 0.43 & 0.16 \\
\hline & D3 & 4.10 & 0.71 & 0.25 & 10.21 & 0.82 & 0.11 & 799.5 & 0.13 & 0.02 \\
\hline & D4 & 5.39 & 0.72 & 0.41 & -17.87 & 1.35 & 0.37 & 685.4 & 0.23 & 0.06 \\
\hline \multirow{5}{*}{$\begin{array}{l}\text { Livin } \\
\text { g } \\
\text { roo } \\
\text { m }\end{array}$} & A1 & 10.97 & 0.48 & 0.29 & 16.06 & 0.60 & 0.11 & & & \\
\hline & A3 & 16.36 & 0.21 & 0.16 & 19.36 & 0.67 & 0.13 & 942.1 & 0.17 & 0.01 \\
\hline & D1 & 19.89 & 0.07 & 0.01 & 18.57 & 0.63 & 0.10 & 951.4 & 0.13 & 0.01 \\
\hline & D3 & 19.8 & 0.07 & 0.01 & 7.26 & 0.96 & 0.13 & 987.2 & 0.06 & 0.003 \\
\hline & D4 & 18.03 & 0.15 & 0.06 & -3.09 & 1.02 & 0.26 & 1113.2 & 0.13 & 0.02 \\
\hline
\end{tabular}

